\title{
REVIEW
}

\section{Ratio-based trophic niche breadths of fish, the Sheldon spectrum, and the size-efficiency hypothesis}

\author{
Sifford Pearre, Jr. \\ Department of Oceanography, Dalhousie University, Halifax, Nova Scotia B3H 4J1, Canada
}

\begin{abstract}
Traditional approaches to diet analysis in fish established that niche breadth increases as the fish grows. However, this appears to be artefactual, influenced by sampling, measurement, and statistical difficulties. On a ratio scale, niche breadths appear to be characteristic of a species and (generally) constant as the fish grows. In general there seems to be no equivalent to Roughgarden's 'between-phenotype-component' in ratio-based niche widths of fish. From the data available, there also appears to be no consistent trend of niche breadth among fish predator species of different mean sizes. Similarities to and differences from Ursin's log weight-ratio analysis are discussed. Assuming equal or predictably declining prey biomass in equal logarithmic length intervals (a Sheldon spectrum), a constant logarithmic (ratio) niche breadth means a constant or declining effective prey biomass pool as predators become larger. This contrasts with the generally expanding prey biomass pool postulated in the size-efficiency hypothesis. When prey biomass equilibrium can be assumed, declining productivity with size will further reduce resources available to increasingly large predators. A declining resource base would act to offset any size-related gains in metabolic or foraging efficiency.
\end{abstract}

\section{INTRODUCTION}

There has been considerable recent interest in the way in which aquatic foragers, particularly fish, utilize their prey resources. Much of the effort has been directed toward modeling optimal foraging under varying assumptions, but a large body of data has been gathered on prey selection and actual gut contents of fish collected under field conditions. Gut content analysis is subject to many problems and open to misinterpretation (Pearre 1974, Persson 1979, Hyslop 1980, Durbin et al. 1983), but laboratory feeding can seldom give a good representation of natural prey abundances and microdistributions (Reeve 1980, Kremer 1982, Oiestad 1982) and may, if we wish to examine natural trophodynamics, be ultimately even more difficult to interpret.

It is common to represent the diet breadth of a fish species in terms of the range of sizes of prey organisms found in the guts (Rojas de Mendiola 1974, Popova 1978, Hunter 1981, Cohen \& Lough 1983) and this range is generally found to increase as a fish grows However, range is a very poor measure statistically because of its dependence on sample size (the number of prey items counted). This in turn is affected in 2 ways by predator size. (1) Field samples usually contain different numbers of fish in different size classes, as controlled by gear selectivity and the population structure. Typically, the modal predator size is near or below the mean of the predator size range. If the expected number of prey per predator were equal, this is where we should typically find the widest prey size range. This source of error could be eliminated by randomly subsampling equal numbers of predators from each size class. (2) The number of prey per predator generally increases with predator size (Detwyler \& Houde 1970, Conway 1980, Kane 1984). Thus, if equal numbers of predators in each size class are examined, the prey sample size usually increases with predator size, leading to maximum range in the largest predator size class. The relation of the number of prey per predator to predator length varies among species, so there is no hope of a priori calibration.

A typical result of using range to examine feeding patterns is that, while the upper bound increases with predator size (unless there are few large predators in 
the sample), the minimum prey size increases little or remains constant over large ranges of predator sizes (Villiers 1981, Hunter 1981, McCullough \& Stanley 1981, Govoni et al. 1983). This has fostered the impression that large predators can utilize all of the resource range of smaller ones, as well as larger prey, giving them a competitive advantage (Brooks \& Dodson 1965).

At the cost of a considerable loss of information, we could correct the bias by restricting counts to equal numbers of prey per predator size class, most simply by random discard of data a posteriori. It seems, however, both easier and better to discard range as a measure of niche width, and instead adopt a statistical measure such as standard deviation which is independent of sample size. Roughgarden $(1972,1974)$, quantifying Elton's (1927) suggestion that an animal's ecological niche may be characterized by its feeding niche, has defined niche dimensions in terms of prey sizes and standard deviations, and partitioned components of niche variance between and within phenotypes. However, Roughgarden's analysis may be more suitable to animals of relatively constant body size (e.g. birds) than to fish, as the variation in prey sizes taken by a whole population may not so much reflect the predator species' trophic specialization (Roughgarden 1979) as the range of predator sizes examined.

Thus, even good statistical techniques cannot assure good ecological or physiological sense, and we are undoubtedly limited in our ability to perceive prey sizes as a predator would. For instance, measuring small and large prey with the same apparatus introduces constant absolute error, and we are more apt to place 7 and $10 \mathrm{~mm}$ prey in different size classes than prey of 0.07 and $0.1 \mathrm{~mm}$. As larger fish generally eat larger prey, this means that we will be biased to perceive a larger number of prey size classes in the diets of large than of small fish. I will call this the 'precision problem', and it will turn out to be important in several contexts. A second and related difficulty arises from our perception of prey size differences as absolute. R. A. Myers (pers. comm.) suggested the following heuristic conundrum: 'If a whale eats krill ranging from 2.5 to $3.5 \mathrm{~cm}$ in size, and a copepod eats diatoms ranging from 5 to $100 \mu \mathrm{m}$, which has the greater diet breadth?' (Pearre unpubl.). Ursin (1973) proposed the use of a ratio scale: "half as big' and 'twice as big' differ by the same amount from 'just fine'. One such ratio scale can be obtained by substituting the coefficient of variation $\left(={ }^{\prime} \mathrm{CVH}^{\prime}\right)$ for standard deviation (by normalizing the latter by the mean prey size).

Another ratio scale can be obtained by using logarithmically transformed prey size data: calculation of a standard deviation of these $\left(={ }^{\prime} \mathrm{SLH}\right)$ is tantamount to a ratio operation because differences between $\log$-transformed quantities are actually ratios of the untransformed data. There are both precedents and good reasons for using log-transformed prey size data:

(1) A number of plots of prey-size distributions found in the literature suggest log-normality rather than strict normality (Ursin 1973, Gladfelter \& Johnson 1983). However, this can be deceptive: if a distribution is composed of prey from a wide range of predator sizes (as in the cited works), and if as usual mean prey size changes with predator size, the total distribution will be biased to the predator size class with the greatest prey sample size (number). This can give the appearance of skewness or log-normality even if the prey size distributions within each predator size class are symmetrical. Properly, prey size distribution within each predator size class should be normalized (e.g. to mean $=0, \mathrm{SD}=1$ ) before addition.

(2) Normal (or symmetrical) prey-size spectra may themselves be artefacts. If digestion time of prey is size-dependent, as seems likely, we expect relatively more remains of large prey than small, i.e. a biasing towards large sizes (see Durbin et al. 1983). If so, the expected digestion-time relation is exponential, and so an appropriate transformation to correct it would be logarithmic on prey size. However, there are at present few data to support this. Other than the studies reviewed by Durbin et al. (1983), only Mills et al. (1984) address this question in fish. These authors indeed found dependence of evacuation rate on prey size in young Perca flavescens, but at this point, it is unrealistic to consider the relation defined for the general case.

(3) Log-transformed prey size distributions have often improved the fit of prey size to predator size regressions (Pearre 1980a, 1982). In fact, if the variance in prey size is proportional to the mean, as is often the case, some transformation to make them independent is necessary for valid significance testing of the relation of the mean.

(4) Because small predators usually eat small prey, logarithmic interval recording of prey sizes at least partially solves the 'precision problem' above. Unfortunately, it is rare to find this done, because of impracticality in the measurement methods. Scatter-plots of prey and predator sizes expressed as log prey size greatly improve definition of prey sizes of small predators (Minami 1981, 1982) but are also rare.

The 2 ratio-based indices ( $\mathrm{SLH}$ and $\mathrm{CVH}$ ) turn out to be useful in slightly different ways, as will be seen below, and the behavior of both in predators of different sizes will be examined. Preliminary exploration of these indices using a subset of the present data showed no distinct trend of niche width with increasing predator size (Pearre unpubl.). Based on those results, this study takes as its central hypothesis that there is no 
general positive relation of ratio-based niche width to fish size, either within or between species. A lack of relationship cannot, of course, be proven in the sense that some observable trend can, and so as many data sets as could be found and analysed were culled from the literature. These were, as expected, not all equally useful for the analysis, and limitations of different types will be discussed. Throughout this paper, the convention for notation of prey and predator will be ' $\mathrm{H}$ ' and ' $\mathrm{P}$ ', respectively.

\section{MATERIALS AND METHODS}

Materials: data sources and formats. All data were obtained from literature sources, but these were originally recorded in different ways so that some translation and interpretation was necessary. Broadly, the data presentations were either tabular or as scattergrams (plots of predator size and prey size). Because of the problems of differential digestion of items held in the stomach for different periods, and of differences in digestion rates of large vs small prey (Durbin et al. 1983, Hahm \& Langton 1984), data expressed as prey weights could not be used, although weighing is probably the simplest measurement to make. Prey girth or width is probably the best measurement (Ursin 1973, Pearre 1980b, Hulsman 1981) but seldom provided. The most commonly measured dimension, overall prey length, was used for this study, with the implicit assumption that there is no substantial systematic bias in its relation to prey width or fresh prey weight.

The most valuable source of data was a series of manuscript reports authored and co-authored variously by W. E. Barraclough, D. G. Robinson, and J. D. Fulton from 1967 through 1969 (see literature cited under Barraclough and/or Robinson). They present tabular data on lengths and numbers of prey in each predator of a large number of species, and have the advantage of supplying prey size classes recorded in approximately logarithmic intervals (see 'Introduction'). These comprise very large data sets for some species, covering a considerable predator size range, have superior resolution of prey numbers per predator size class, and were taken over a relatively long time span. Of the many species examined in these studies, I have chosen those with the greatest abundances, seasonal and yearly continuity, and predator size ranges, in order to help define the shapes of regressions (see below). The information from these reports has been combined by species and will be referred to as 'BRF' data. Kane (1984) has presented tabular data on prey sizes in 4 size classes of cod and haddock larvae; these have proven useful despite the limited range of predator sizes. Nishiyama \& Hirano (1983) present tabular data on the prey of 50 walleye pollock larvae, and Shelbourne (1962) gives data on Oikopleura prey (the only taxon present) of plaice larvae.

Among data presented as scattergrams, one of the most useful sets is that on Pacific hake larvae by Sumida \& Moser (1980), which contains information on the numbers of prey in each predator/prey size class. The main limitation of these data is, again, a narrow predator size range, but they are of particular interest because they can be compared to a small BRF data set on the same species. Similarly, Berner's (1959) data on the prey of the northern anchovy can be compared to Arthur's (1976) data on this species, Arthur's report also including data on 2 other species. Hunter \& Kimbrell's (1980) data on prey of larval and juvenile Pacific mackerel is outstanding in detail and predator size range covered, and all of these authors provide prey weightings i.e. numbers of prey in each prey/predator size group (designated 'entries' below). A recent data set by Pflug \& Pauley (1984) contains approximate prey weightings for the smallmouth bass Micropterus dolomieui. These data are especially welcome as there are comparatively few on freshwater fish.

The data sets mentioned above (24) are the only ones that contained information on prey numbers per predator/prey size class, and have been grouped as my 'primary' (A) data sets (Table 1). Most of the scattergrams found in the literature give only an unweighted point at each predator/prey size combination. For large piscivorous predators, such as pike or African tigerfish, such representations may be adequate, as individually eaten large prey items are apt to have been few in number and carefully measured.

However, for filter-feeders or other planktivores, the lack of point weighting probably causes the numbers of small prey in each predator class to be underestimated relative to large prey, because of factors mentioned above. Prey size means calculated from such data should thus be overestimated. On the other hand, the decreased central tendency should also increase estimated variance, so to some extent the biases in at least CVH should be self-cancelling. However, as the amounts of bias in the 2 factors are not proportional, the total error of each index probably differs between data sets. Despite these disadvantages, a number of scattergram data sets were analysed; these are termed 'secondary' (B) data sets and may be useful as a check on the generality of conclusions drawn from the primary sets (Table 2).

Methods: data treatment. Scattergram data plots were digitized using either a Kontron 'MOP 40' or a Gentian 'Hi-State' digitizer, the latter feeding directly to a data program in Dalhousie University's Control Data Cyber 170-730 computer. Predator sizes in computer-digitized data sets were subsequently rounded 
Table 1. List and basic statistics of primary ('A') data sets. $\bar{P}=$ logarithmic mean length of predators used in regressions (see text); $\mathrm{n}=$ number of predator size classes; $N_{E}=$ number of $H, P$ pairs ('entries'); $N_{H}=$ number of prey in predator size classes used $\left(N_{E} \geqslant 3\right)$

\begin{tabular}{|c|c|c|c|c|c|}
\hline Species & $\overline{\mathrm{P}}(\mathrm{mm})$ & n & $N_{E}$ & $\mathrm{~N}_{\mathrm{H}}$ & Source \\
\hline Lumpenella longirostris & 21.2 & 9 & 37 & 469 & $\operatorname{BRF}(1967-1969)^{\circ}$ \\
\hline Lumpenus sagitta & 33.5 & 19 & 95 & 666 & $\operatorname{BRF}(1967-1969)^{\circ}$ \\
\hline Ammodytes hexapterus & 40.4 & 63 & 787 & 9101 & $\operatorname{BRF}(1967-1969)^{\circ}$ \\
\hline Hexagrammos decagrammus & 37.7 & 28 & 162 & 2371 & $\operatorname{BRF}(1967-1969)^{\circ}$ \\
\hline Gasterosteus aculeatus & 71.8 & 40 & 417 & 20993 & $\operatorname{BRF}(1967-1969)^{\circ}$ \\
\hline Oncorhynchus keta & 88.9 & 84 & 1566 & 94463 & $\operatorname{BRF}(1967-1969)^{\circ}$ \\
\hline O. gorbuscha & 88.9 & 71 & 1168 & 77424 & $\operatorname{BRF}(1967-1969)^{\circ}$ \\
\hline O. kisutsch & 145.3 & 60 & 364 & 9242 & $\operatorname{BRF}(1967-1969)^{\circ}$ \\
\hline O. tschawytscha & 118.7 & 25 & 126 & 4565 & BRF $(1967-1969)^{\circ}$ \\
\hline O. nerka & 93.9 & 55 & 562 & 22581 & $\operatorname{BRF}(1967-1969)^{\circ}$ \\
\hline Salmo gairdnerii & 169.1 & 29 & 141 & 2555 & $\operatorname{BRF}(1967-1969)^{\circ}$ \\
\hline Clupea pallasii & 113.8 & 110 & 962 & 43406 & $\operatorname{BRF}(1967-1969)^{\circ}$ \\
\hline Merluccius productus & 6.4 & 7 & 29 & 139 & $\operatorname{BRF}(1967-1969)^{\circ}$ \\
\hline M. productus & 4.9 & 39 & 552 & 1809 & Sumida \& Moser (1980) \\
\hline Theragra chalcogramma & 9.5 & 27 & 169 & 830 & Nishiyama \& Hirano (1983) \\
\hline Melanogrammus aeglefinus & 6.1 & 4 & 67 & 1839 & Kane (1984) \\
\hline Gadus morhua & 6.1 & 4 & 61 & 1122 & Kane (1984) \\
\hline Scomber japonicus & 11.5 & 24 & 220 & 355 & Hunter \& Kimbrell (1980) \\
\hline Engraulis mordax & 4.8 & 12 & 94 & 272 & Berner (1959) \\
\hline E. mordax & 3.9 & 6 & 71 & 118 & Arthur (1976) \\
\hline Sardinops sagax & 5.8 & 16 & 80 & 195 & Arthur $(1976)$ \\
\hline Trachurus symmetricus & 5.7 & 13 & 175 & 463 & Arthur $(1976)$ \\
\hline Pleuronectes platessa & 7.7 & 8 & 114 & 2414 & Shelbourne (1953) \\
\hline Micropterus dolomieui & 224.3 & 5 & 37 & 567 & Pflug \& Pauley (1984) \\
\hline$\Sigma: 24$ data sets, 22 species & & 758 & 8056 & 297.959 & 9 studies \\
\hline
\end{tabular}

Table 2. List and basic statistics of secondary ('B') data sets

\begin{tabular}{lrrrl}
\hline Species & $\overline{\mathrm{P}}(\mathrm{mm})$ & $\mathrm{n}$ & $\mathrm{N}_{\mathrm{E}}$ & Source \\
\hline Thunnus alalunga & & & 79 & Uotani et al. (1981) \\
T. albacares & 6.0 & 6 & 150 & Uotani et al. (1981) \\
T. maccoyi & 5.4 & 7 & 148 & Uotani et al. (1981) \\
Pagrus major & 5.1 & 7 & 239 & Omori (1980) \\
Hydrocyon vittatus & 58.7 & 49 & 166 & Jackson (1961) \\
Esox lucius & 314.3 & 29 & 80 & Domanevsky (1963) \\
Chanda commersoni & 424.3 & 25 & 95 & Nair \& Nair (1981) \\
Theragra chalogramma & 117.8 & 9 & 109 & Nakatani \& Maeda (1983) \\
Lutjanus griseus & 7.3 & 23 & 102 & Starck \& Schroeder (1971) \\
Pleuronicthyes cornutus & 108.0 & 19 & 54 & Minami (1982) \\
Limanda yokohamae & 5.5 & 8 & 155 & Minami (1981) \\
Sardinops melanostricta & 5.3 & 30 & 42 & Yokota et al. (1961) \\
Scomber japonicus & 42.8 & 11 & 164 & Yokota et al. (1961) \\
S. tapeinocephalus & 52.1 & 34 & 68 & Yokota et al. (1961) \\
Sphyraena japonica & 59.1 & 28 & Yokota et al. (1961) \\
Sillago sihama & 96.2 & 19 & 63 & Yokota et al. (1961) \\
Etrumeus micropus & 63.5 & 36 & 41 & Yokota et al. (1961) \\
Plecoglossus altjelis & 57.6 & 9 & 73 & Yokota et al. (1961) \\
Evinnis (Ev.) japonica & 53.4 & 15 & 181 & Yokota et al. (1961) \\
Trachurus japonica & 27.3 & 31 & 194 & Yokota et al. (1961) \\
Engraulis (En.) japonica & 38.0 & 38 & 2449 & 9 studies \\
E 21 data sets, 21 species & 44.7 & 439 & & \\
\hline
\end{tabular}


to produce the maximum number of predator size clases containing 3 or more prey 'entries', i.e. 3 or more independent prey size estimates whether equal or different.

Most of the data were expressed as prey length classes rather than width. Although prey widths are a more useful measure in many ways (Ursin 1973, Pearre 1980b, Hulsman 1981), and although for most statistical purposes they could be used interchangeably, data given as prey widths (Arthur 1976, Hunter \& Kimbrell 1980, Omori 1980, Sumida \& Moser 1980) were converted to prey lengths, for uniformity, by the equation

$$
\mathrm{L}=3.52 \mathrm{~W}^{0.966}
$$

which was inverted from copepod width-weight and length-weight relations reported by Pearre (1980b). Kane's (1984) data were given as prey weights derived from width measurements by Pearre's (1980b) expression; these were reconverted to lengths by the same relation.

Linear or log-transformed prey-size data ('A' data only) were normalized, i.e. transformed to mean $=0$, standard deviation $=1$, in each predator size class and summed over the range of predator size classes. The resultant normalized prey distributions were analysed by Minitab ${ }^{\circledR}$ using the ' $\alpha$ ' test criterion for normality (Ryan et al, 1980),

Standard deviations were calculated on all data having 3 or more entries in any predator size class (above). Coefficients of variation were corrected for sample size as recommended by Sokal \& Rohlf (1981, p. 59). All regressions were weighted if possible and appropriate; regressions against predator size of coefficients of variation of prey size (CVH) and standard deviations of the logarithm of prey size (SLH) were weighted by the number of prey observed in each predator size class $\left(N_{H}\right)$ in the 'A' data (Sokal \& Rohlf 1981). From regressions on all ' $A$ ' data sets taken together, the number of prey in each predator size class $\left(\mathrm{N}_{\mathrm{H}}\right)$ was found to be proportional to the number of $\mathrm{H}, \mathrm{P}$ pairs, or 'entries' $\left(\mathrm{N}_{\mathrm{E}}\right)$ as:

$$
\mathrm{N}_{\mathrm{H}}=\mathrm{kN}_{\mathrm{E}}^{1.15} \quad \mathrm{t}_{(684)}=16.2(\mathrm{p} \ll 0.001)
$$

Therefore, as $N_{H}$ was not specified for 'B' data, their regressions and statistics were weighted by $N_{E}$. Weighting the ' $B$ ' data regressions by $N_{E}$ usually helped by reducing the non-normality of residuals of such regressions relative to that of regressions on unweighted statistics (see below). For between-species regressions, $\overline{\mathrm{CVH}}$ and $\overline{\mathrm{SLH}}$ and their estimated slopes against predator size $\left(\beta_{\mathrm{SLH}}\right.$ and $\left.\beta_{\mathrm{CVH}}\right)$ were weighted by the inverse of their variances (Cramér 1945).

Residuals of all regressions on both A \& B data sets were tested for normality using the ' $\alpha$ ' criterion (Ryan et al. 1980). For several of the data sets, especially in the ' $A$ ' group, statistics on those predator size classes which were persistently identified as having large standardized residuals or leverage were eliminated in order to satisfy the criterion of normality of residuals, even where this resulted in a substantial reduction of the overall ' $n$ '. All statistics, including means, were calculated after elimination of predator size groups containing less than 3 prey entries (above) and of predator size classes contributing substantially to nonnormality of the residuals. Although predator size distributions may often be selected post-capture in order to provide 'representative' samples, and hence be neither normal nor log-normal, the mean predator size was calculated as a weighted logarithmic mean, as in general these had lower coefficients of variation than arithmetic mean sizes.

The variance of the slopes $\left(\beta_{\mathrm{SLH}}, \beta_{\mathrm{CVH}}\right)$ was much higher in predators of small mean size than large (Fig. $3 b$ \& 4 b) possibly due in part to imprecision in measurements of both small prey and small predators. As such non-normality in the distribution of variance can lead to erroneous significance tests - usually overly conservative - a data transformation which can normalize the distribution is desirable. In this case the ' $\mathrm{Y}$ ' (mean slope) values were transformed by raising to various odd powers (odd in order to retain signs) and the regression retested. This procedure succeeded in considerable reduction of the non-normality, but the regressions did not become significant at any power tested (up to 7). The untransformed original regression can therefore be considered valid (C.A. Field pers. comm.).

Some of the BRF data (in a period of April to July 1968, Barraclough et al. 1968) and some of Nishiyama \& Hirano's (1983) data showed large numbers of euphausiid or copepod eggs in the guts of several fish species. This raised a difficulty as to the effective prey size, which would vary according to whether the eggs were individually selected, selected in large groups or egg clusters, or passively filtered (Ursin 1973). In order to avoid bias in either direction, data on all fish in a sample of species (in the BRF sets) found to have more than 10 eggs in any individual were discarded; 10 or fewer eggs were assumed to have been individually selected.

There are many other published data on prey and predator sizes which have been reported only as means or else as proportions (usually percentages); these could not be used in this study. It was also necessary to omit data sets in which measurements of only 1 or a few catagories of prey were reported - e.g. fish prey only or copepods only - as the true mean prey size generally must be calculated from differing proportions of different items seasonally or as the predator grows. 


\section{SOURCES OF ERROR}

A possible source of error is the variation of predator size class width. As was pointed out above, this can influence the perceived prey-size distribution, with a wide predator size class perhaps causing biased means. If the true mean prey size is increasing with predator size, wider predator size classes may have inflated variance estimates due to superimposition of non-congruent prey frequency distributions. It is not possible to correct for this without prior knowledge of the mean prey size-to-predator size function for each species, and no allowance was made for it here. As size class intervals are likely to be larger in larger predator species, this error will tend to be conservative with respect to the hypothesis of this paper.

A problem with many of the currently available data is that few concern adult fish, which by traditional hypotheses should have the broadest feeding niches. Many of the studies concern only larvae, which may have different feeding modes and other types of adaptation than the adults, for instance pelagic feeding of flatfish larvae vs epibenthic feeding in the older stages. As discussed below, early stages may be adapted for life in 'nursery areas' which may, at least temporarily, have unusual characteristics in their prey size spectra. For these reasons, studies involving a wide range of predator sizes and integrating several seasons are most valuable.

By the same arguments, inter-species comparisons would be most definitive if made between equivalent life stages of the various species, instead of the comparisons made here between larvae of some and juveniles or adults of others. If the hypothesis of this paper is true, however, the niche breadths of all stages should be similar, so comparisons as done here should be valid. If, on the other hand, the more traditional hypothesis of expanding niche breadth with growth is correct, the comparisons should exaggerate any positive between-species slope, and so this form of analysis is very conservative.

All of the above sources of error are conservative with respect to the no-slope hypothesis, and together with the sampling, perceptual and measurement problems including the 'precision problem' mentioned earlier, can be expected to give a positive bias to estimates of slopes of the relation of niche width to predator length, both within and between species (or to obscure real negative relations). Another source of error, of unpredictable bias, is the uncertainty of estimating slopes from data sets in which there is a lot of Y-variance compared to that in X (Pearre 1980a). In practice this means data sets in which the range of predator sizes covered was short, and this was often true, especially of larval data. The problem is exacer- bated by the requirement to discard predator data with less than 3 prey 'entries', in order to compute variances: this often meant discarding data near the limits of the predator size ranges. Possible effects of this error source will be examined and discussed below.

\section{RESULTS}

Examination of the summed normalized prey size distributions showed generally symmetrical overall distributions but usually with less skewness in the logtransformed versions. Almost all were markedly leptokurtic (which could be normalized by a log-transform of the frequency axis), probably indicating prey selectivity, but this is not considered to endanger regressions or significance testing (C.A. Field pers. comm.) The results support, but do not necessitate, use of the log-prey size transformation.

Results of successive steps in the analysis of diet breadth in the medium-sized BRF (see Materials and Methods') data set on prey of Ammodytes hexapterus (sand lance) are shown in Fig. 1 \& 2. Although neither scattergram (Fig. 1a \& 2a) is weighted, an immediate improvement in the error distribution can be seen when the prey sizes are log-transformed, and this is reflected in the estimated standard deviation of untransformed and transformed data (Fig. 1b \& 2b). $\mathrm{SLH}$ and CVH were found, as expected, to be very highly correlated ( $p<<0.001$ ) in almost all data sets.

Tables 3 and 4 give the values of the weighted mean niche breadth measures and the slope of the niche breadth with predator size, for each species of the ' $A$ ' and 'B' data groups, respectively. Although a number of significant slopes - positive and negative - are recorded, the overall impression is that slopes are slight to non-existent, i.e. that in general niche breadth measured on a ratio scale does not change appreciably as a fish grows. This impression is confirmed by the weighted means of the slopes, which are slightly negative for SLH in both data sets, slightly positive for $\mathrm{CVH}$, but not close to significance in any case. These might be considered approximations to the ideal fish' regressions.

Fig. 3 \& 4 show the behavior of the weighted mean SLH and its slope, $\beta_{\text {SLH }}$ as functions of predator length at the weighted mean predator length for each species in the ' $A$ ' and ' $B$ ' data sets, respectively. Again, little or no trend is noticeable in the data, this time on a between-species basis (similar plots for $\overline{\mathrm{CVH}}$ look nearly identical). Table 5 gives the slopes of these lines for both indices and their significance tests. Again, the slope of mean niche widths are slight; those for $\overline{\mathrm{SLH}}$ are negative but insignificant in both data sets, while 
Fig. 1. (a) Ammodytes hexapterus. Unweighted scattergram of prey and predator lengths from 'BRF' data sets, 1967-1969. (b) A. hexapterus. Mean and standard deviation of prey sizes in predator size classes which have 3 or more prey-size/predator-size pairs ('entries') $=N_{E} \geq 3 ;$ BRF data
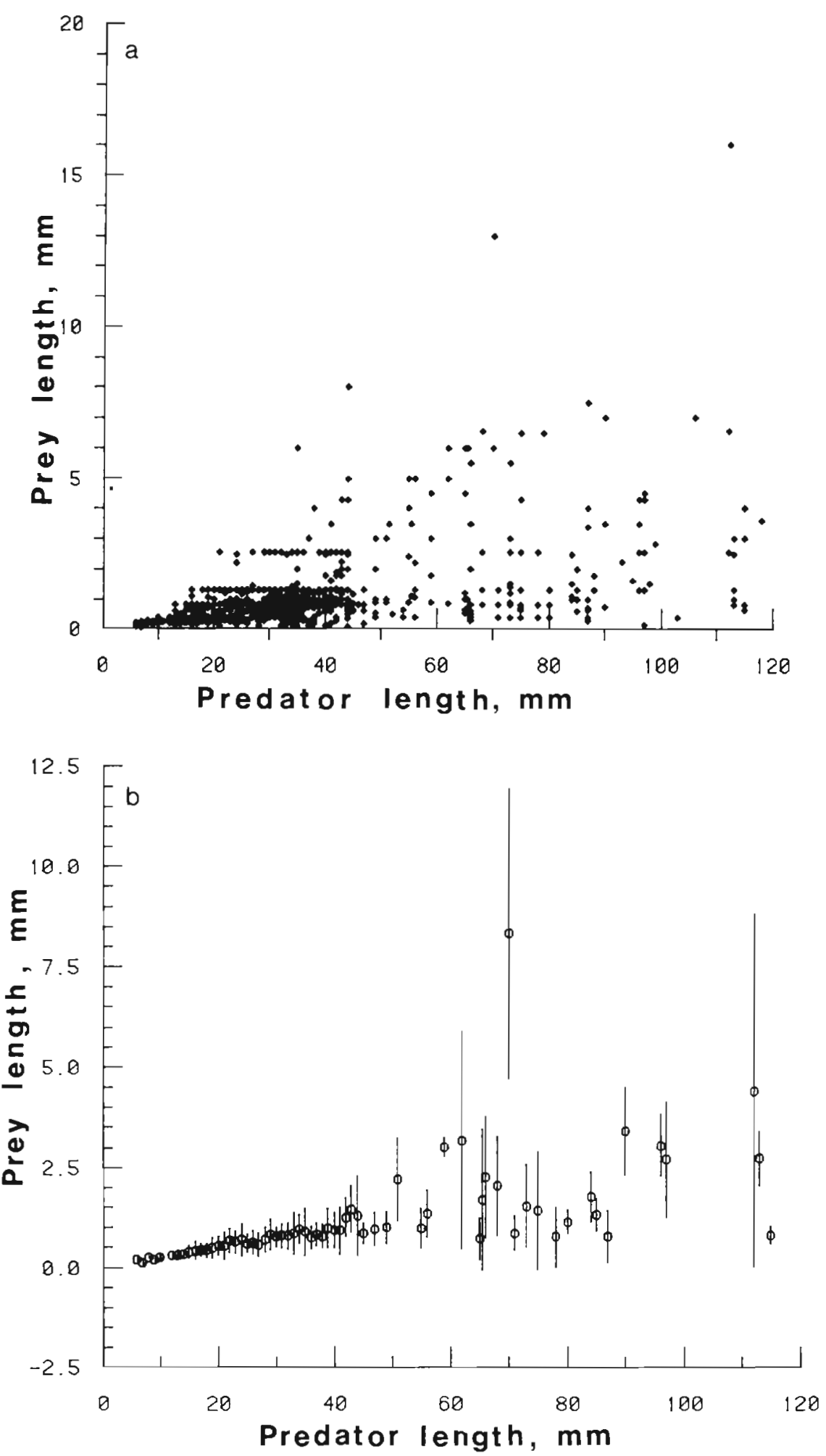

the between-species slope for $\overline{\mathrm{CVH}}$ is significantly positive (at the 0.05 level) in the ' $A$ ' data (apparently related to the lengths of the data sets, as discussed above) and significantly negative in the ' $\mathrm{B}$ ' data. The regressions of slope $\left(\beta_{\mathrm{SLH}}\right.$ and $\left.\beta_{\mathrm{CVH}}\right)$ against mean pre- dator length shows no significant trends in any of the cases. This means that there is no tendency for larger species (or longer data records) to have niche-width slopes different on average from small ones. However, despite the overall apparent lack of slopes of niche 

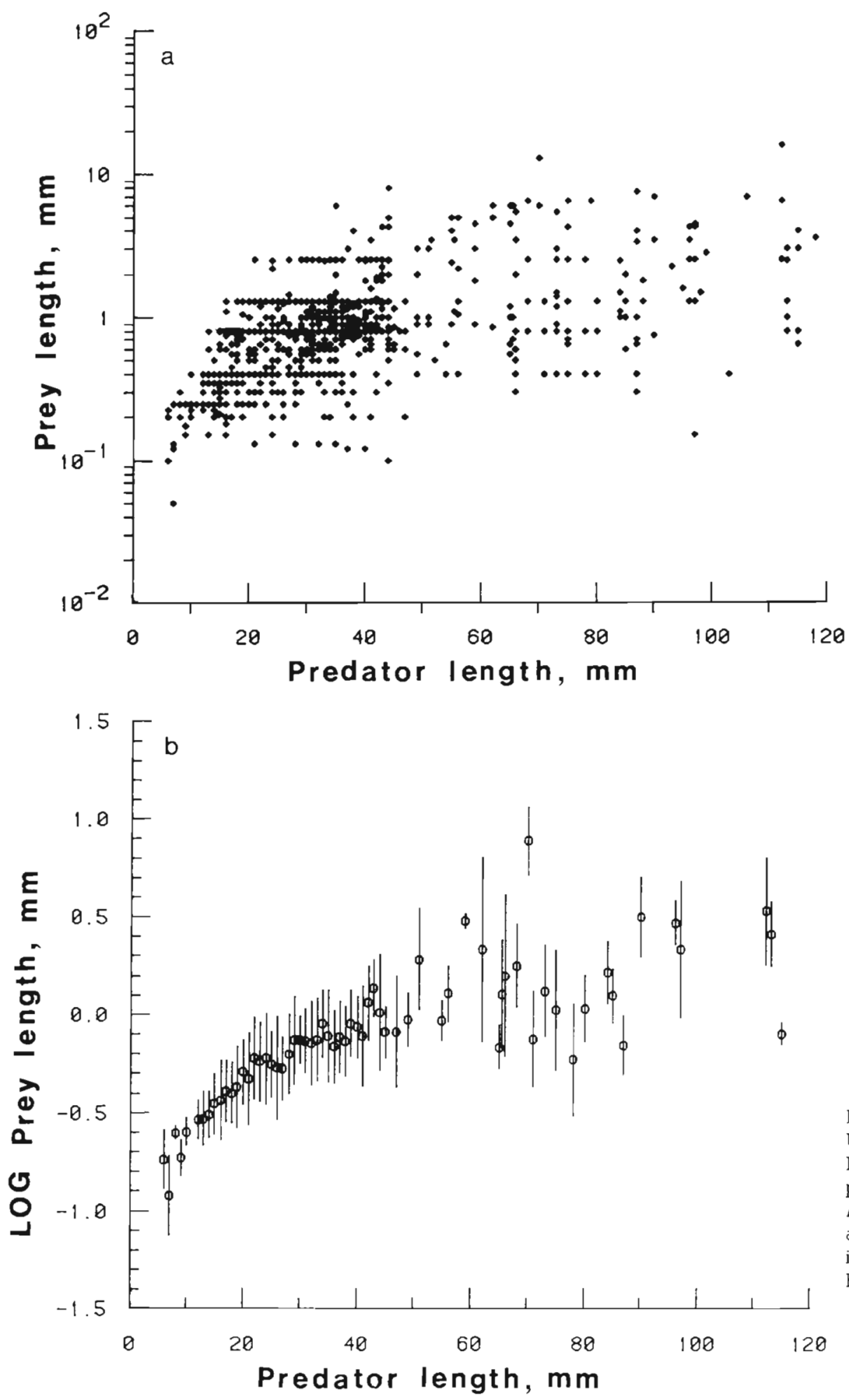

Fig. 2. (a) Ammodytes hexapterus. Unweighted scattergram data, as in Fig. 1a, but with prey size (length) plotted on a logarithmic scale. (b) $A$. hexapterus. Mean and standard deviations of $\log _{10}$-transformed prey sizes in predator size classes with $N_{E} \geq 3$; BRF data. These are estimates of SLH at each predator size

width versus size within species, there appear to be greater than randomly expected numbers of significant regressions, of both positive and negative slopes, in both data sets (Tables $3 \& 4$ ). Most of the heterogeneity in slopes occurred in data on very small predators (Fig. $3 b \& 4 b)$. This might either indicate real differences in evolutionary strategies controlling the size-related behavior of niche widths in larval fish, or be simply a statistical artefact caused by the small predator size ranges used for most larval feeding studies (above). Regressions of the absolute values of these slopes ( $\beta_{\mathrm{SLHF}}$ ' and ' $\beta_{\mathrm{CVH}}$ ') against predator size range, as esti- 
Table 3. Regressions on 'A' (weighted) data sets, of form $\mathrm{Y}=\alpha+\beta(\mathrm{P}-\overline{\mathrm{P}})$, where $\mathrm{Y}=\mathrm{SLH}$ or $\mathrm{CVH}$; $\alpha=\overline{\mathrm{SLH}}$ or $\overline{\mathrm{CVH}}(\mathrm{SD})$

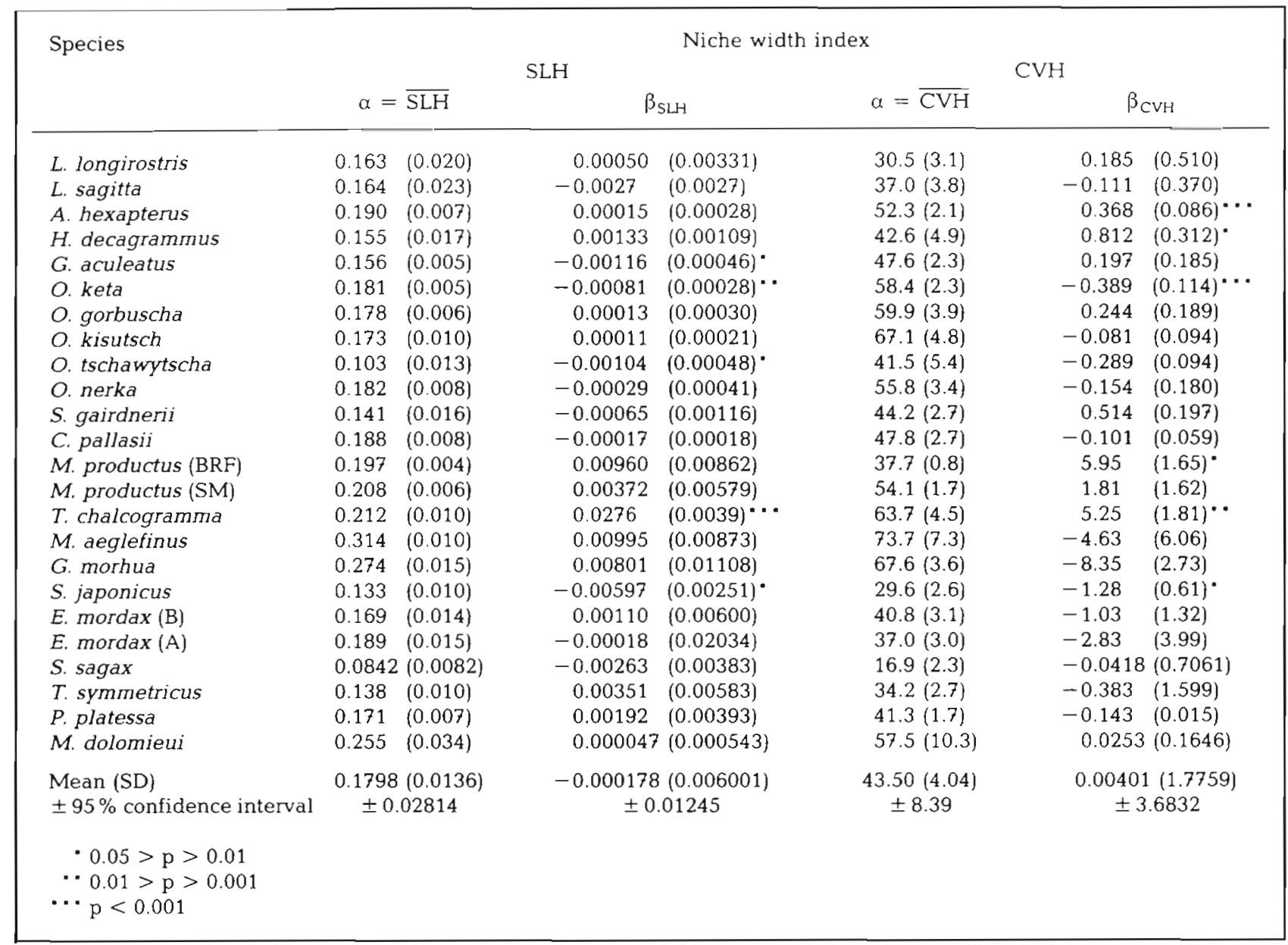

mated by the standard deviation of predator size classes, indicate that for both indices in both the ' $A$ ' and ' $B$ ' data sets the scatter of the slopes was greatest in the short data sets and that the slopes approached zero as data sets became longer.

SLH appears to be somewhat less variable than CVH (Tables 3 \& 4), and in the ' $\mathrm{A}$ ' data set, $\overline{\mathrm{CVH}}$ increased significantly as the length of the data set (predator size range, above) increased. SLH is also more direct to calculate and probably has more statistical propriety (e.g. CVH would be very sensitive to systematic biases in the calculation of mean prey size) and so seems the preferable index for most uses.

The 2 data groups contain 4 data sets which are paired, and consistency in the statistics of these can help determine the validity of the niche breadth indices. As can be seen from Fig. 5, the pairs appear to have remarkable similarity. All except the 2 studies on Theragra chalcogramma are very closely grouped, and appear to indicate species-characteristic niche widths, with mackerel (Scomber japonicus) the narrowest of the group. As T. chalcogramma appears to be unusual in having a strong positive relation of niche width to size (at least in the young stages examined in these studies), the calculated mean niche width must vary with the mean size, so the separation on the $Y$-axis is not surprising. The $\mathrm{Y}$-intercepts of the T. chalcoamma regressions are not, in fact, statistically different.

Several other data sets have been presented in which only information on mean prey size and its standard deviation are given (or derivable); statistics on mean CVH's calculated from these are given in Table 6. Among the fish data, only one has significant slope and that is negative. In contrast to the results of Roughgarden's $(1974,1979)$ analysis, none of the terrestrial lizard species examined by Schoener \& Gorman (1968) or Roughgarden (1974) show significant changes of ratio-based niche widths among predators of different head sizes, and there appears to be no trend among species of different mean size. For comparisons with this type of data, of course, $\mathrm{CVH}$ is the more useful index. 
Table 4. Regressions on 'B' (unweighted) data sets, of form $Y=\alpha+\beta(P-\bar{P})$, where $Y=C V H$ or SLH; $\alpha=\overline{C V H}$ or $\overline{\mathrm{SLH}}(\mathrm{SD})$

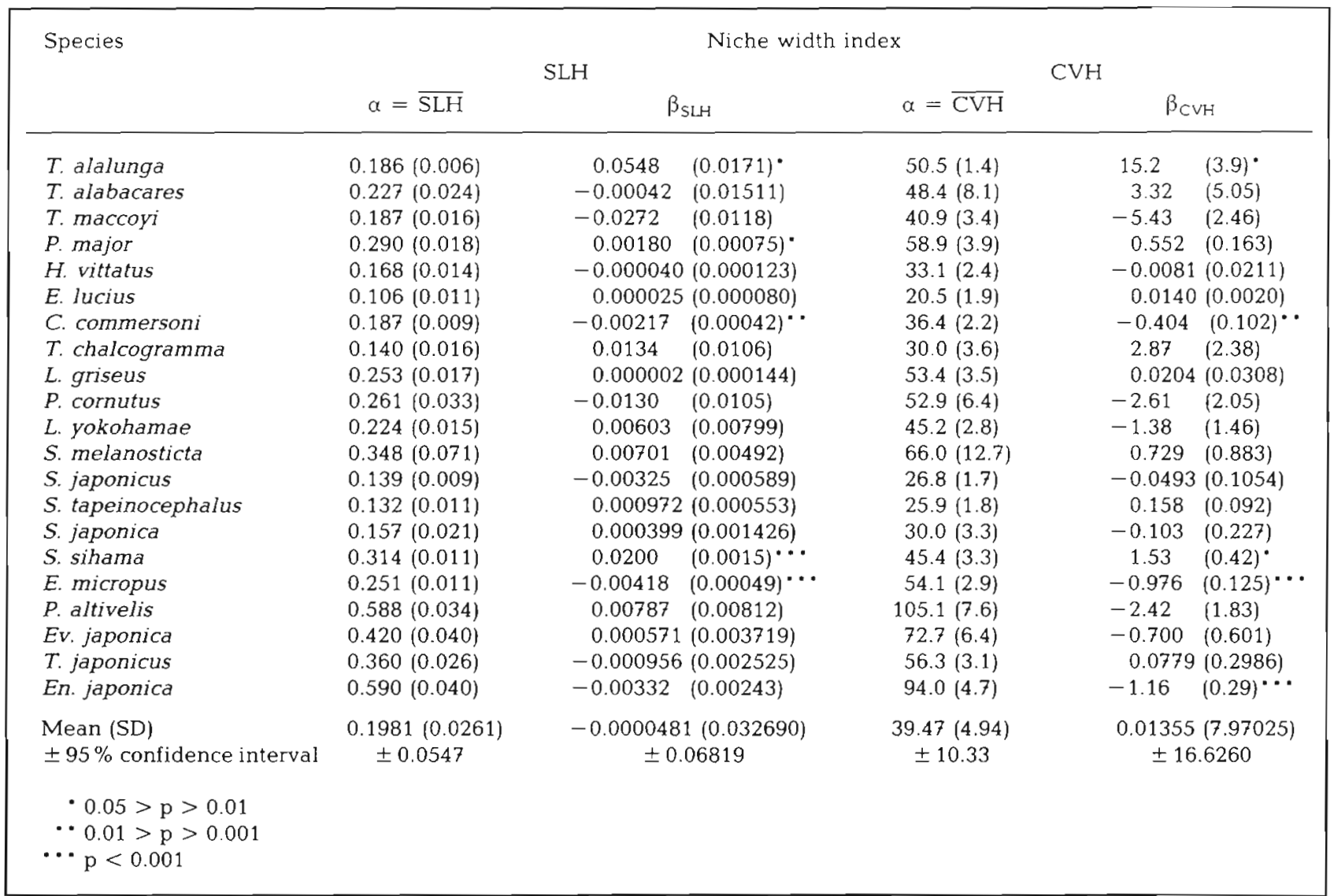

\section{DISCUSSION}

The foregoing analysis and all the data comparisons pertain to fish predators which swallow their prey whole - sometimes called 'engulfing' - but include both classic filterers such as herring, and piscivorous predators such as walleye pollock and tuna, as well as fish such as mackerel with ability to feed in either mode. There are also typically pelagic species (all the above), demersal fish such as cod and hake, and benthic feeders (snailfish). In addition, the analysis encompasses both marine (all the above) and freshwater fish (smallmouth bass in the 'A' group, pike and tigerfish (Hydrocyon vittatus] in 'B' group), and also anadromous species (salmon, trout) and 2 euryhaline species (stickleback and Chanda commersoni). A similar lack of relation of a ratio measure of diet breadth to predator size has been found in other engulfing predator types both terrestrial (Table 6) and aquatic (Pearre unpubl.).

A potential source of problems in food niche-width analysis is in sizes of prey available, which can lead to a narrowing of the effective niche breadth as a pre- dator grows (e.g. Pearre 1980a). Another set of problems can arise from seasonal changes in the size spectrum of available prey. In this case, mean prey size can actually decrease as a predator grows, and this has even more severe consequences for niche breadth. This is probably not a significant problem in openocean areas, but may be important in small lakes or relatively closed embayments. This is also a problem with annual predator species, but there are very few of these in the marine environment - the snailfish Liparis tanakai is probably the only annual species in this study (Kawasaki et al. 1983). In longer-lived species, it is sometimes possible to obtain data on several year classes simultaneously, and this is another great advantage of the BRF data, but is true of some of the other data sets (especially 'B' data sets) as well.

Agger \& Ursin (1976), Arntz \& Ursin (1981), Livingston (1983) and Hahm \& Langton (1984) have estimated feeding niche breadths of various fish using Ursin's (1973) formulation of feeding niche, involving summation of the logarithms of predator weights divided by prey weights. Assuming that the problems inherent in weight measurements of partially digested prey can be 


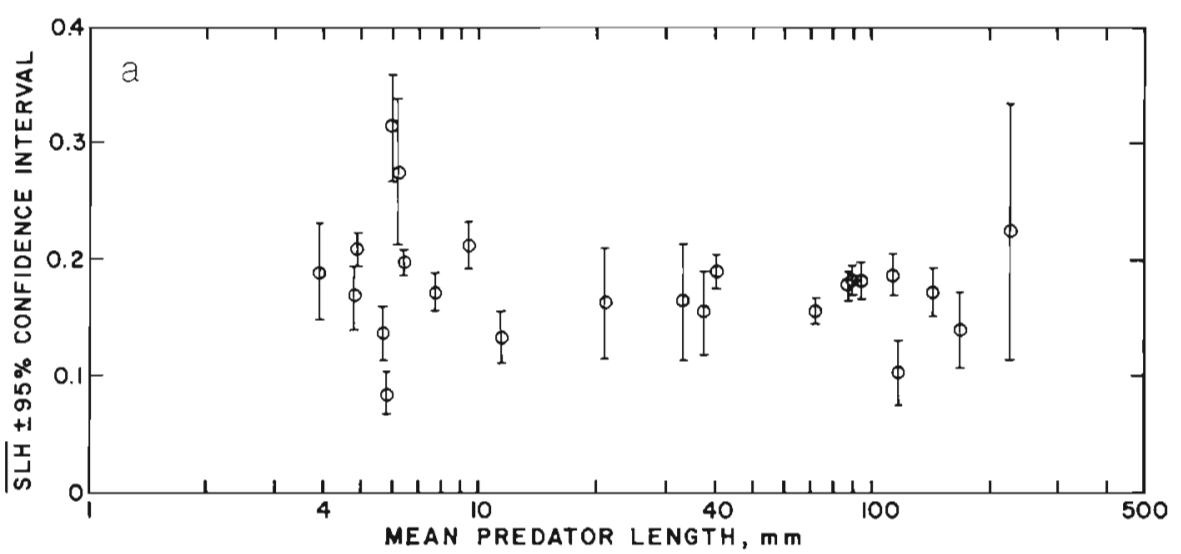

Fig. 3. (a) $\overline{\mathrm{SLH}}=\mathrm{SLH}$ weighted by number of prey items $\left(\mathrm{N}_{\mathrm{H}}\right)$ versus weighted mean length of predator species in each ' $A$ ' (primary) data set. SLH values as mean \pm $95 \%$ confidence interval. Predator mean lengths plotted on logarithmic scale for convenience. See Table 3 for details. (b) $\beta_{\mathrm{SLH}}=$ slope of individual SLH/P regressions versus mean predator length, for ' $A$ ' data group

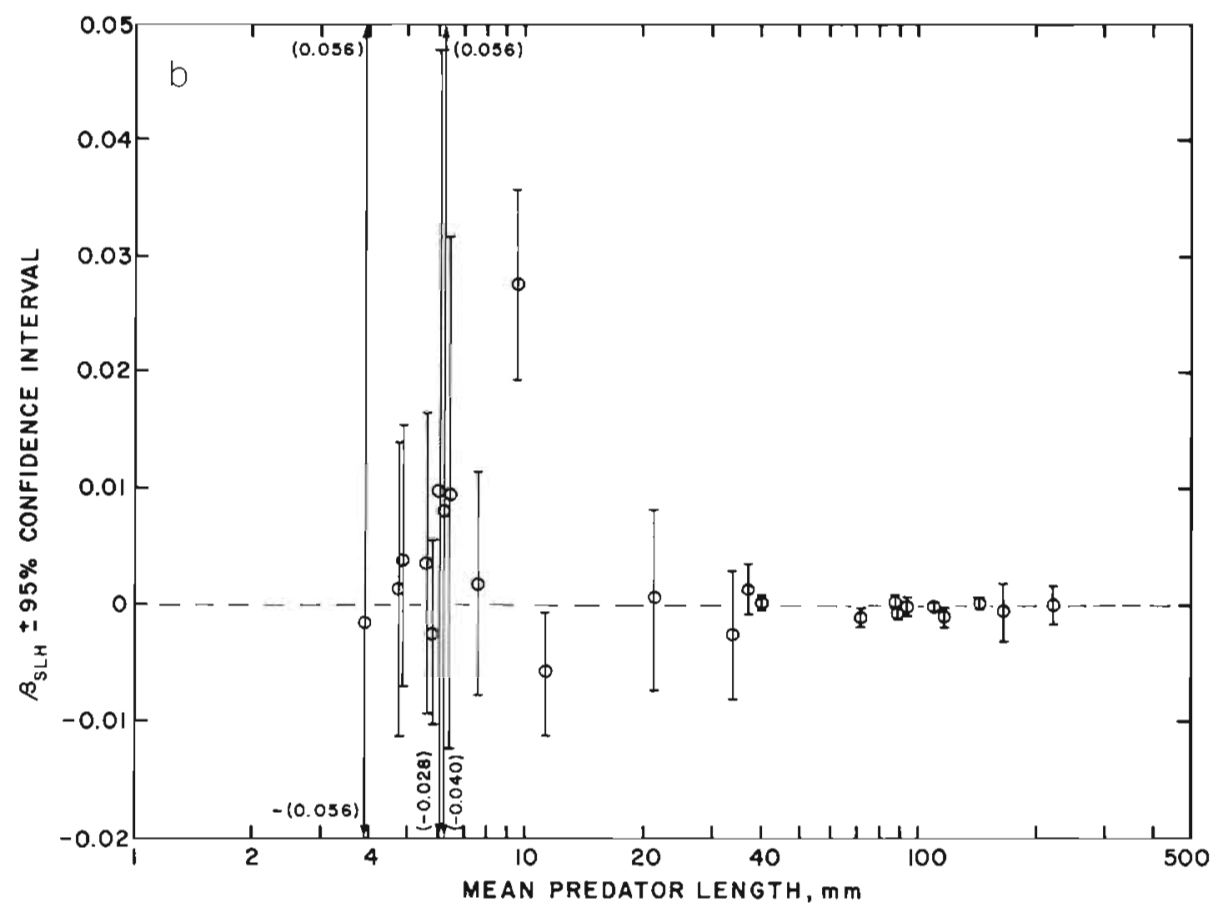

overcome (see 'Materials and Methods') - such as by estimation of weights from length or width measurements - this approach provides an excellent tool for examining the relation of a whole species population in a particular area to its prey pool. The indices of niche breadth derived by Ursin's method are superficially similar to those presented here, but the purposes differ. Firstly, of course, Ursin's method does not allow investigation of niche width changes with predator growth, one of the principal objectives of this study. Also, normalization to predator sizes, while allowing estimation of a trophic niche for a whole population or species, means that the niche derived is only relative, i.e. to predator size. As Roughgarden (1972, 1974, 1979) pointed out, the breadth of a feeding niche should be a function of the food alone; its 'position', i.e. mean prey size and its relation to predator size, should be kept separate. Perhaps of more practical impor- tance, if the optimal ( $\cong$ mean; Elton 1927 ) relation of food size to predator size changes as the predator grows, this approach will produce a niche which is broader than the true niche due to the effective addition of displaced normal curves. Also, as standard deviations of prey sizes are generally not independent of mean prey sizes (see above), this formulation could lead to biased estimates of niche width for, say, 2 equal sized fish with different mean prey sizes (Andersen 1982). Finally, while prey weight is of paramount importance in calculating the benefit to the predator of the prey capture, it is likely (and assumed by most optimal foraging models) that selection of prey is done on the basis of length (= encounter probability, escape speed), width (=ingestion, retention), or projected area (= visibility) (cf. Werner 1974, Pearre 1980b).

Kane (1984) calculated a feeding niche breadth for co-occurring cod and haddock larvae (from the same 

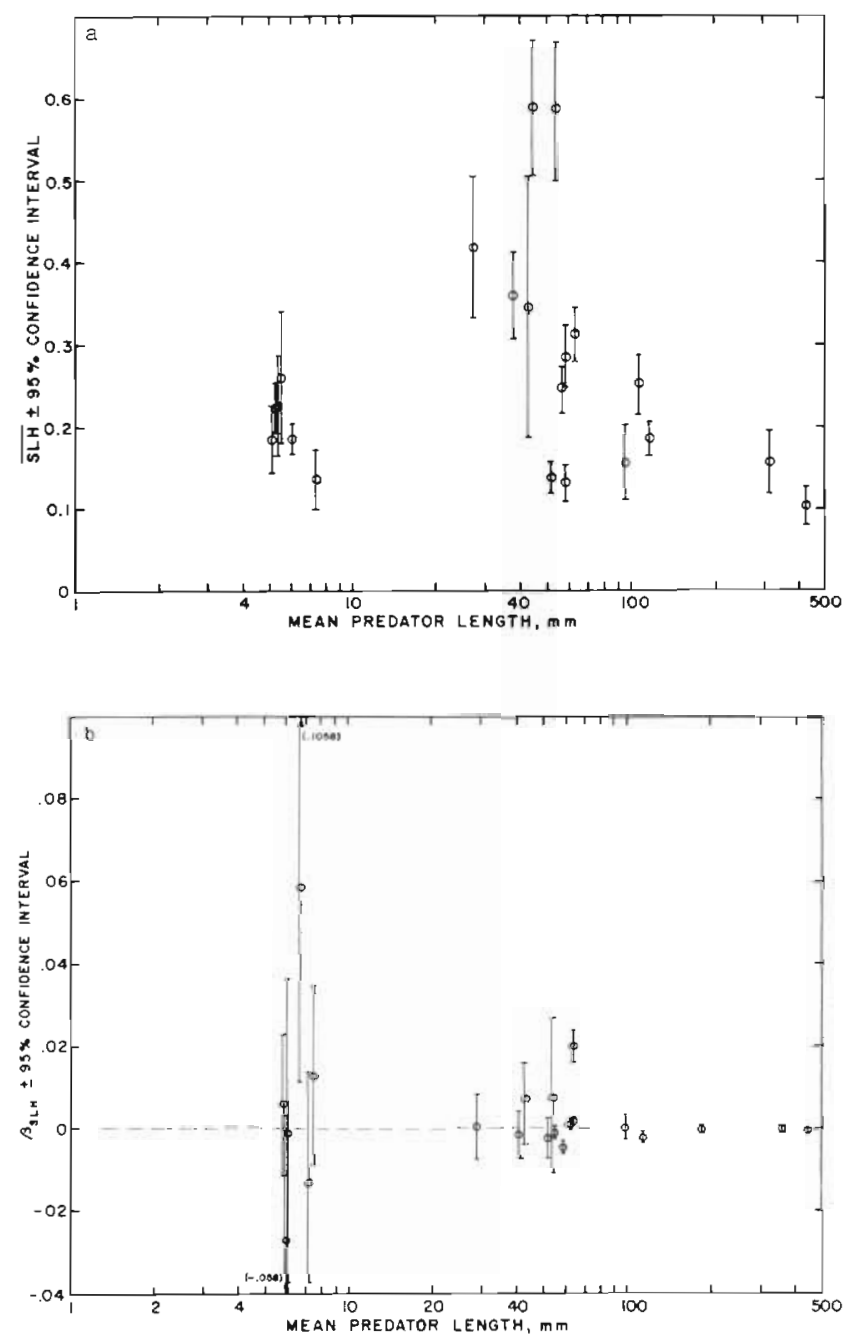

Fig. 4. (a) $\overline{\mathrm{SLH}}$ (as above) versus mean predator length for ' $\mathrm{B}$ ' (secondary) data group. (b) $\beta_{\mathrm{SLH}}=$ slope of individual SLH $/ \mathrm{P}$ regressions versus mean predator length, for ' $B$ ' data group. Note scale change
Table 5. Slopes (b) of regressions of mean niche width per species against species mean length and of species regression slopes ( $\beta$ ) against species mean length

\begin{tabular}{|c|c|c|c|}
\hline \multirow[b]{2}{*}{$\begin{array}{l}\text { Niche } \\
\text { width } \\
\text { index }\end{array}$} & \multirow[b]{2}{*}{$\begin{array}{c}\text { Data } \\
\text { set }\end{array}$} & \multicolumn{2}{|c|}{$\begin{array}{c}\text { Statistics: } \\
\text { mean } \\
(\mathrm{SD}) \\
\pm 95 \% \text { confidence interval }\end{array}$} \\
\hline & & $\begin{array}{c}a=\overline{\mathrm{SLH}} \text { or } \overline{\mathrm{CVH}} \\
a=\mathrm{a}_{1}+\mathrm{b}_{1} \mathrm{P} \\
\mathrm{b}_{1}\end{array}$ & $\begin{array}{c}\beta=\beta_{\mathrm{SLH}} \text { or } \beta_{\mathrm{CVH}} \\
\beta=\mathrm{a}_{2}+\mathrm{b}_{2} \mathrm{P} \\
\mathrm{b}_{2}\end{array}$ \\
\hline \multirow[t]{2}{*}{ SLH } & A & $\begin{array}{l}-0.0106 \\
(0.0149) \\
\pm 0.0309\end{array}$ & $\begin{array}{r}3.3 \times 10^{-7} \\
\left(47.3 \times 10^{-7}\right) \\
\pm 98.1 \times 10^{-7}\end{array}$ \\
\hline & B & $\begin{array}{r}-0.000204 \\
(0.000141) \\
\pm 0.000295\end{array}$ & $\begin{array}{c}-0.000290 \\
(0.000637) \\
\pm 0.001332\end{array}$ \\
\hline \multirow[t]{2}{*}{$\mathrm{CVH}$} & A & $\begin{array}{c}0.103^{\circ} \\
(0.047) \\
\pm 0.097\end{array}$ & $\begin{array}{r}-0.00194 \\
(0.00153) \\
\pm 0.00317\end{array}$ \\
\hline & $B$ & $\begin{array}{c}-0.0556 \\
(0.0237) \\
\pm 0.0496\end{array}$ & $\begin{array}{c}0.000163 \\
(0.000203) \\
\pm 0.000425\end{array}$ \\
\hline
\end{tabular}

area as those examined by Hahm \& Langton 1984) by the method of Feinsinger et al. 1981. This is based on proportions of species rather than on sizes, and indicated a broader niche for cod larvae than for haddock in contrast to the results from SLH and CVH (Table 3). However, it is interesting that this index also appears invariant or slightly declining over the predator size ranges examined (Kane's Fig 8a).

The general invariance of feeding niche width, as

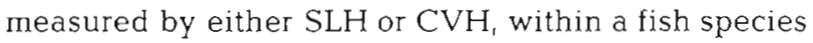

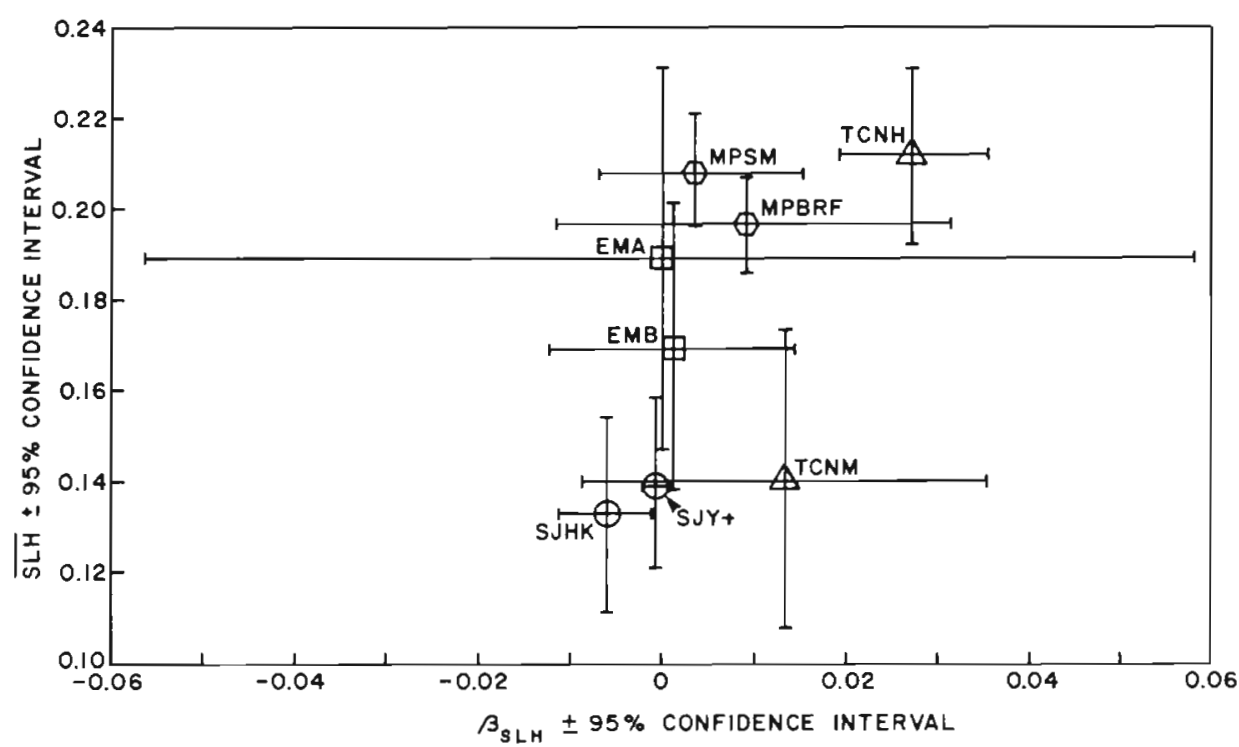

Fig. 5. Mean values and $95 \%$ confidence intervals for SLH plotted against species regression slopes $\left(\beta_{\mathrm{SLH}}\right)$ for pairs of studies on the same species: MPSM $=$ Merluccius productus (Sumida \& Moser 1980): MPBRF $=M$. productus ('BRF': see text); EMA = Engraulis mordax (Arthur 1976); $\mathrm{EMB}=$ E. mordax (Berner 1959); SJYt $=$ Scomber japonicus (Yokota et al. 1981): SJHK $=S$. japonicus (Hunter \& Kimbrell 1980); TCNM = Theragra chalcogramma (Nakatani \& Maeda 1983); $\mathrm{TCMH}=T$. chalcogramma (Nishiyama \& Hirano 1983). Note: SJY + and TCNM are 'B' data sets (see text) 
Table 6. Relation of CVH to predator size in data sets listing only means and standard deviations (or another dispersion measure). Statistics as mean $\pm 95 \%$ confidence interval

\begin{tabular}{|c|c|c|c|c|c|c|}
\hline (a) Fish species & $\bar{P}$ & $\mathrm{n}$ & $\overline{\mathrm{CVH}}$ & & $\beta$ & Source \\
\hline Stizostedion vitreum vitreum & 238 & 11 & $29.6 \pm 5.1$ & 0.0024 & \pm 0.0507 & Knight et al. (1984) \\
\hline Noturus munitus & 39.0 & 6 & $6.97 \pm 0.70$ & -0.0025 & \pm 0.0079 & Miller (1984) \\
\hline Deltentosteus quadrimaculatus & 21.5 & 14 & $6.11 \pm 1.40$ & 0.0118 & \pm .0751 & Villiers $(1980)$ \\
\hline Brevoortia patronus & 5.5 & 4 & $50.3 \pm 5.6$ & -2.84 & $\pm 2.15^{\circ}$ & Stoecker \& Govoni (1984) \\
\hline \multicolumn{7}{|l|}{ (b) Anolis (lizard) species } \\
\hline A. richardi ${ }^{\mathrm{a}}$ & $18.2^{\mathrm{b}}$ & 8 & $52.2 \pm 11.1$ & 0.63 & $\pm \quad 3.12$ & Schoener \& Gorman (1968) \\
\hline A. aeneus & $13.9^{\mathrm{b}}$ & 8 & $48.0 \pm 9.1$ & -0.31 & \pm 4.22 & Schoener \& Gorman (1968) \\
\hline A. roquet ${ }^{a}$ & $14.7^{\mathrm{b}}$ & 11 & $99.0 \pm 34.6$ & 7.01 & \pm 17.7 & Schoener \& Gorman (1968) \\
\hline A. marmoratus ferreus & $15.8^{\mathrm{C}}$ & 5 & $51.0 \pm 5.3$ & 1.32 & \pm 3.03 & Roughgarden (1974) \\
\hline \multicolumn{7}{|c|}{ a Data on males and females combined (no significant between-sex differences) } \\
\hline \multicolumn{7}{|c|}{${ }^{b}$ Head length, mm } \\
\hline \multicolumn{7}{|l|}{${ }^{\circ}$ Jaw length, mm } \\
\hline$\cdot 0.05>p>0.01$ & & & & & & \\
\hline
\end{tabular}

obviates the need for a 'between-phenotype component' (Roughgarden 1972, 1974) for fish, and probably also for other engulfers. A regression approach (instead of ANOVA, Roughgarden 1972) to nichewidth analysis allows the niche to be described in terms of a relation of predator size to some ratio measure of niche breadth. A separate regression can then be used to relate the niche position (mean prey size) to predator size - a question not addressed in this study.

Sheldon et al. (1972), on the basis of an extensive literature search as well as their own work, proposed that particle biomass within equal logarithmic intervals of particle diameter was essentially constant in the world's oceans. By this hypothesis, the spectrum should be essentially 'flat' (i.e. a straight line) and of zero slope. Modeling approaches (Kerr 1974, Platt \& Denman 1977, 1978) suggested flat distributions with slight negative slopes, though freshwater studies have tended to find zero net slope but with a 'peaky' spectrum (Sprules et al. 1983). This may not be contradictory; McCave (1984) suggested on theoretical grounds that young particle distributions are peaky but tend to flatten (with zero slope) as they age. This should mean that biomass sampled over a whole growing season should tend to be smoothed and flattened, and results by Hargrave et al. (1985) - an essentially flat spectrum from equivalent spherical diameters of $10^{-3}$ through $100 \mathrm{~mm}$ (>16 octaves) - seem to support this.

If the feeding niche width (on a logarithmic scale) of a fish is constant as the fish grows, then the prey-size 'window' in the spectrum from which prey are chosen stays constant on that scale. Assuming that the predator will utilize all types of prey which are both available and economical (in the sense of Werner 1974,
1977), and that the mean prey size increases as the fish grows, we can say that the useful potential prey biomass for that fish varies with the mean prey size as the slope of the Sheldon spectrum. While this slope is not yet absolutely known, it is at least not positive over any large regions, so that over periods or spaces other than seasonal or local (e.g. Arntz \& Ursin 1981), the useful food resource cannot be increasing as a fish grows. It is possible, however, that fish may take advantage of temporary or regional peakiness for spawning and early larval growth, as peaky spectra are characteristic of many typical inshore spawning and nursery grounds.

Similarly, between-species analysis of $\overline{\text { SLH }}$ shows only non-significant (negative) slopes in both data sets (Fig. 3a \& 4a; Table 5). The apparent positive slope of $\overline{\mathrm{CVH}}$ in the ' $\mathrm{A}$ ' data group appears to be confounded by the data set lengths (above), but is probably not meaningful when balanced against $\overline{\mathrm{SLH}}$ and the negative slope for $\overline{\mathrm{CVH}}$ in the ' $\mathrm{B}$ ' group. This means that for large species, the useful food biomass is probably no larger and may be smaller than for small ones. Reasoning solely on the basis of a mean prey/predator size relation (niche position), Ware (1980) reached a similar conclusion that the prey biomass available to cod should decrease as (cod weight) ${ }^{-0.08}$. In fact, the decline in food resources with predator size is probably, in general, considerably more severe than that indicated by the slope of the spectrum of standing biomass. In a steady-state ecosystem, including virtually any ecosystem followed through 1 or more annual cycles, predators are utilizing not biomass but production (Kerr 1974). As productivity generally declines with size (Elton 1927, Fenchel 1974, Kerr 1974, Banse \& 
Mosher 1980, Peters 1983, Huntley \& Boyd 1984) the food resources (production/biomass $\times$ biomass) within any constant or even slightly expanding biomass interval must decrease as mean size increases, wherever the Sheldon (biomass) spectrum has near-zero or negative slope.

Brooks \& Dodson (1965) proposed what has become known as the 'size-efficiency hypothesis', or 'SEH' (Hall et al. 1976), to explain the dominance of large zooplankters over small species in environments free of fish predators. This proposes dominance by superior competitive ability, and one of the cornerstones is that superior competitive ability derives in part from the ability of large competitors to eat 'a wider range of prey sizes than small ones' (Brooks \& Dodson 1965). In essence, large species are assumed able to utilize essentially all of the prey size spectrum available to small ones, plus particles too large for the small ones. Other aspects of the SEH have been attacked on various grounds (Hall et al. 1976, Lynch 1977, Frost 1980, DeMott \& Kerfoot 1982, Tessier \& Goulden 1982), but Hall et al. commented that In the absence of ... a definite body size relationship for the minimum particle size ingested, we must assume that available food concentration. . increases with [herbivore] body size' [italics mine] (in accordance with the size-related increase in maximum particle size ingested). At least for fish, this assumption no longer appears tenable, and support for the SEH must rest on arguments of size-related metabolic or foraging efficiency. Gerritsen (1984) argues forcefully that the SEH can be supported without assuming that larger swimming foragers have increasing spectra of available particle sizes, though he feels the assumption is still likely to be true for single-particle raptorial feeders. However, Gerritsen's model does not consider the effect of relative prey size on cost-benefit ratios. Several experimental studies have failed to support the SEH in assemblages of zooplankton (Neill 1975, Lynch 1978, DeMott 1982) and fish (Lammens 1982), apparently because larger predators cannot outcompete small ones if the available food particle size is such that the small ones can use it more economically. The results of this analysis indicate that increasing consumption of large prey is generally accompanied by decreasing consumption of small ones, so that as mean or optimal prey size changes, older or larger fish move out of competition with younger or smaller ones. Thus, it would appear that modeling approaches should include realistic particle-size (and perhaps productivity) spectra and cost/ benefit analyses as well as biomass levels of food.

Acknowledgements. I thank D. W. Welch for considerable time spent in writing Fortran programs, for sage advice on data treatment, and both David and Masako Welch for translations of Japanese papers. I thank M. A. Bousfield for transla- tion of Russian work, and E. D. Wangersky for artful and professional graphics. I particularly thank C. A. Field of the statistics consulting group, Dalhousie Department of Mathematics, for advice on statistical procedures. Others, including R. A. Myers and J. A. Runge, have contributed to the development and presentation of ideas. I also thank R. W Doyle and E. G. Merinfeld for critical reviews of earlier versions of the manuscript and many helpful suggestions.

Permission to use the excellent but unpublished 'BRF' data set (see text) was given by J. A. Thomson of Fisheries and Ocean Canada, Nanajmo, B. C.; and by D. G. Robinson, one of the principal authors. Without these data, the conclusions of the analysis would be much less firm. I thank B. Sumida for encouragement and help with unpublished details of her data on feeding of Pacific hake larvae, and R. L. Knight for unpublished details of his data on walleye pike. Partial funding for this project was provided by a grant from the Chesapeake Bay Foundation

\section{LITERATURE CITED}

Andersen, K. P. (1982). An interpretation of the stomach contents of fish in relation to prey abundance. Dana 2: $1-50$

Agger, P., Ursin, E. (1976). Food and food preferences of the grey gurnard. Coun. Meet. int. Coun. Explor. Sea C.M.ICES/F: 41

Arntz, W E., Ursin, E. (1981). On the estimation of food preference parameters when food concentrations are not known. An application of Anderson's stomach analysis model. Coun. Meet. int. Coun. Explor. Sea C.M.-ICES/L: 40

Arthur, D. K. (1976). Food and feeding of larvae of three fishes occurring in the California Current, Sardinops sagax Engraulis mordax, and Trachurus symmetricus. Fish. Bull. U. S. 74: $517-530$

Banse, K., Mosher, S. (1980). Adult body mass and annual production/biomass relationships of field populations. Ecol. Monogr 50: 355-379

Barraclough, W E. (1967a). Number, size, and food of larval and juvenile fish caught with a two boat surface trawl in the Strait of Georgia April 25-29, 1966. Fish. Res. Bd Can. MS Rept. 922: 1-54

Barraclough, W. E. (1967b). Number, size, and food of larval and juvenile fish caught with an Isaacs-Kidd trawl in the surface waters of the Strait of Georgia April 25-29, 1966. Fish. Res. Bd Can., MS Rept. 926: 1-79

Barraclough, W E. $(1967 \mathrm{c})$. Number, size composition and food of larval and juvenile fish caught with a two-boat surface trawl in the Strait of Georgia June 6-8, 1966. Fish. Res. Bd Can., MS Rept. 928: 1-58

Barraclough, W. E., Fulton, J. D. (1967). Number, size composition and food of larval and juvenile fish caught with a two-boat surface trawl in the Strait of Georgia July 4-8, 1966. Fish. Res. Bd, Can., MS Rept. 940: 1-82

Barraclough, W. E., Fulton, J. D. (1968). Food of larval and juvenile fish caught with a surface trawl in Saanich Inlet during June and July 1966. Fish. Res. Bd Can., MS Rept. 1003: $1-78$

Barraclough, W. E., Robinson, D. G., Fulton, J. D. (1968). Number, size composition, weight and food of larval and juvenile fish caught with a two-boat surface trawl in Saanich Inlet April 23-July 21, 1968. Fish. Res. Bd Can., MS Rept. 1004: 1-305

Berner, L., Jr. (1959). The food of the larvae of the northern anchovy Engraulis mordax. Bull. inter-Am. trop. Tuna Commn 4: $1-22$ 
Brooks, J. L., Dodson, S. I. (1965). Predation, body size, and composition of plankton. Science 150: 28-35

Cohen, R. E., Lough, R. G. (1983). Prey field of larval herring Clupea harengus on a continental shelf spawning area. Mar. Ecol. Prog. Ser. 10: 221-222

Conway, D. V P. (1980). The food of larval blue whiting, Micromesistius poutassou (Risso), in the Rockall area. J. Fish Biol. 16: 709-723

Cramér, H. (1945). Mathematical methods of statistics. (13th printing, 1974). Princeton Univ. Press, Princeton

DeMott, W. B. (1982). Feeding selectivities and relative ingestion rates of Daphnia and Bosmina. Limnol. Oceanogr. 27: 518-527

DeMott, W. B., Kerfoot, W. C. (1982). Competition among cladocerans: nature of the interaction between Bosmina and Daphnia. Ecology 63: 1949-1966

Detwyler, R., Houde, E. D. (1970). Food selection by laboratory-reared larvae of the scaled sardine Harengula pensacolae (Pisces, Clupeidae) and the bay anchovy Anchoa mitchilli (Pisces, Engraulidae). Mar. Biol. 7: 214-222

Domanevsky, L. N. (1963). Procedure for studying the nutrition of predatory fish. Tr. Atlant. n.-i. inst. morsk. rybn. Khoz.; okeanogr. 10: 201-204 (in Russian)

Durbin, E. G., Durbin, A. G., Langton, R. W., Bowman, R. E. (1983). Stomach contents of silver hake, Merluccius bilinearis, and Atlantic cod, Gadus morhua, and estimation of their daily rations. Fish. Bull. U. S. 81: 437-454

Elton, C. (1927). Animal ecology. Sidgwick \& Jackson Ltd Reprint edition Methuen \& Co., London, 1966

Feinsinger, P., Spears, E., Poole, R. W. (1981). A simple measure of niche breadth. Ecology 62: 27-32

Fenchel, T. (1974). Intrinsic rate of natural increase: the relationship with body size. Oecologia (Berl.) 14: 317-326

Frost, B. W. (1980). The inadequacy of body size as an indicator of niches in the zooplankton. In: Kerfoot, W. C. (ed.) Evolution and ecology of zooplankton communities. Univ. Press, New England, p. 742-753

Gerritsen, J. (1984). Size efficiency reconsidered: a general foraging model for free-swimming aquatic animals. Am. Nat. 123: $450-467$

Gladfelter, W. B., Johnson, W S. (1983). Feeding niche separation in a guild of tropical reef fishes (Holocentridae) Ecology 64: 552-563

Govoni, J. J., Hoss, D. E., Chester, A. J. (1983) Comparative feeding of three species of larval fishes in the northern Gulf of Mexico: Brevoortia patronus, Leiostomus xanthurus, and Micropogonias undulatus. Mar. Ecol. Prog. Ser. 13: 189-199

Hahm, W., Langton, R. (1984). Prey selection based on predator/prey weight ratios for some northwest Atlantic fish. Mar. Ecol. Prog. Ser. 19: 1-5

Hall, D. J., Threlkeld, S. T., Burns, C. W., Crowley, P. H. (1976). The size-efficiency hypothesis and the size structure of zooplankton communities. Ann. Rev. Ecol. Syst. 7: $177-208$

Hargrave, B. T., Harding, G. C., Drinkwater, K. F., Lambert, T. C., Harrison, W. G. (1985). Dynamics of the pelagic food web in St. Georges Bay, southern Gulf of St. Lawrence. Mar. Ecol. Prog. Ser. 20: 221-240

Hulsman, K. (1981). Width of gape as a determinant of size of prey eaten by terns. Emu 81: 29-32

Hunter, J. R. (1981). Feeding ecology and predation of marine fish larvae. In: Lasker, R. (ed.) Marine fish larvae: Washington Sea Grant Program, p. 33-77

Hunter, J. R., Kimbrell, C. A. (1980). Early life history of Pacific mackerel, Scomber japonicus. Fish. Bull. U. S. 78 89-101
Huntley, M., Boyd, C. (1984). Food-limited growth of marine zooplankton. Am. Nat. 124: 455-478

Hyslop. E. J. (1980). Stomach content analysis - a review of methods and their application. J. Fish Biol. 17: 411-429

Jackson, P. B. N. (1961). The impact of predation, especially by the tigerfish (Hydrocyon vittatus Cast.) on African freshwater fishes. Proc. zool. Soc. Lond. 136: 603-622

Kane, J. (1984). The feeding habits of co-occurring cod and haddock larvae from Georges Bank. Mar Ecol. Prog. Ser. 16: $9-20$

Kawasaki, T., Hashimoto, H., Honda, H., Otake, A. (1983) Selection of life histories and its adaptive significance in a snailfish Lparis tanakai from Sendai Bay. Bull. Jap. Soc. scient. Fish. 49: 367-377

Kerr, S. R. (1974). Theory of size distributions in ecological communities. J. Fish. Res. Bd Can. 31: 1859-1862

Knight, R. L., Margraf, F. J., Carline, R. F. (1984). Piscivory by walleyes and yellow perch in western Lake Erie. Trans. Am. Fish. Soc. 113: 677-693

Kremer, P. (1982). Effect of food availability on the metabolism of the ctenophore Mnemiopsis mccradyi. Mar. Biol. 71: 149-156

Lammens, E. H. R. R. (1982). Growth, condition, and gonad development of bream (Abramis brama L.) in relation to its feeding conditions in Tjeukemeer. Hydrobiologia 95: 311-320

Livingston, P. A. (1983). Food habits of Pacific whiting, Merluccius productus, of the west coast of North America 1967 and 1980. Fish. Bull. U. S. 81: 629-636

Lynch, M. (1977). Fitness and optimal body size in zooplankton populations. Ecology 58: 763-774

Lynch, M. (1978). Complex interactions between natural coexploiters - Daphnia and Ceriodaphnia. Ecology 59: 552-564

McCave, I. N. (1984). Size spectra and aggregation of suspended particles in the deep ocean. Deep Sea Res. 31: 329-352

McCullough, R. D., Stanley, J. G. (1981). Feeding niche dimensions in larval rainbow smelt (Osmerus mordax). Rapp. P.-v. Réun. Cons. int. Explor. Mer. 178: 352-354

Miller, G. L. (1984). Trophic ecology of the frecklebelly madtom Noturus munitus in the Tombigbee River, Mississippi. Am. Midl. Nat. 111: 8-15

Mills, E. L., Ready, R. C., Jahncke, M., Hanger, C. R., Trowbridge, C. (1984). A gastric evacuation model for young yellow perch, Perca flavescens. Can. J. Fish. Aquat. Sci. 41: $513-518$

Minami, $T$ (1981). The early life history of a flounder Limanda yokohamae. Bull. Jap. Soc. scient. Fish. 47: 1411-1419 (in Japanese)

Minami, T. (1982). The early life history of a flounder Pleuronichthys cornutus. Bull. Jap. Soc. scient. Fish. 48: 369-374 (in Japanese)

Nair, J. R., Nair, N. B. (1981). Prey-predator relationships \& feeding ethology in the glassy perchlet Chanda (= Ambassis) commersoni (Cuv. \& Val.) (Pisces; Centropomidae) Indian J. mar. Sci. 10: 142-147

Nakatani, T., Maeda, T. (1983). Distribution of walleye pollock larvae and their food supply in Funka Bay and the adjacent waters, Hokkaido. Bull. Jap. Soc. scient. Fish. 49, 183-187

Neill, W. E. (1975). Experimental studies of microcrustacean competition, community composition and efficiency of resource utilization. Ecology 56: 809-826

Nishiyama, T., Hirano, K. (1983). Estimation of zooplankton weight in the gut of larval walleye pollock (Theragra chalcogramma). Bull. Plankton Soc. Japan 30: 159-170 
Oiestad, V (1982). Application of enclosures to studies on the early life history of fishes. In: Grice, G. D., Reeve, M. R. (ed.) Marine mesocosms: biological and chemical research in experimental ecosystems. Springer-Verlag, New York, p. 49-62

Omori, M. (1980). Feeding habit of yearling red sea bream (Pagrus major) in Yuya Bay. Bull. Seikai Reg. Fish. Lab. 54: 93-109 (in Japanese)

Pearre, S., Jr (1974). Ecological studies of three westMediterranean chaetognaths. Investigación pesq. 38: 325-369

Pearre, S., Jr. (1980a). Feeding by Chaetognatha: the relation of prey size to predator size in several species. Mar. Ecol. Prog. Ser 3: 125-134

Pearre, S., Jr (1980b). The copepod width-weight relation and its utility in food chain research. Can. J. Zool. 58: $1884-1891$

Pearre, S., Jr. (1982). Feeding by Chaetognatha: aspects of inter-and intra-specific predation. Mar. Ecol. Prog. Ser. 7: $33-45$

Persson, L. (1979). The effects of temperature and different food organisms on the rate of gastric evacuation in the perch (Perca fluviatilis). Freshwat. Biol. 9: 99-104

Peters, R. H. (1983). The ecological implications of body size. Cambridge Univ. Press, Cambridge

Pflug, D. E., Pauley, G. B. (1984). Biology of smallmouth bass (Micropterus dolomieui) in Lake Sammamish, Washington. NW Sci. 58: 118-130

Platt, T., Denman, K. (1977). Organization in the pelagic ecosystem. Helgoländer Meeresunters. 30: 575-581

Platt, T., Denman, K. (1978). The structure of pelagic marine ecosystems. Rapp. P.-v. Réun. Cons. int. Explor. Mer. 173: $60-65$

Popova, O. A. (1978). The role of predaceous fish in ecosystems. In: Gerking, S. D. (ed.) Ecology of freshwater fish production. Blackwell Scientific Publ., London, p. 215-249

Reeve, M. R. (1980). Comparative studies on the feeding of chaetognaths and ctenophores. J. Plankton Res. 2: 381-393

Robinson, D. G. (1969a). Number, size composition, weight and food of larval and juvenile fish caught with a two-boat surface trawl in the Strait of Georgia July 4-6, 1967. Fish. Res. Bd Can., MS Rept. 1012: 1-71

Robinson, D. G. (1969b). Number, size composition, weight and food of larval and juvenile fish caught with a two-boat surface trawl in the Strait of Georgia April 24-25, 1968. Fish. Res. Bd Can. MS Rept. 1067: 1-63

Robinson, D. G., Barraclough, W E., Fulton, J. D. (1968a), Number, size composition, weight and food of larval and juvenile fish caught with a two-boat surface trawl in the Strait of Georgia May 1-4, 1967. Fish. Res. Bd Can., MS Rept. 964: 1-105

Robinson, D. G., Barraclough, W E. Fulton, J. D. (1968b). Number, size composition, weight and food of larval and juvenile fish caught with a two-boat surface trawl in the Strait of Georgia June 5-9, 1967. Fish. Res. Bd Can., MS Rept. 972: 1-109

Rojas de Mendiola, B. (1974). Food of the larval anchoveta
Engraulis ringens J. In: Blaster, J. H. S. (ed.) The early life history of fish. Springer-Verlag, Berlin, p. 277-285

Roughgarden, J. (1972). Evolution of niche width. Am. Nat. 106: $683-718$

Roughgarden, J. (1974). Niche width: biogeographic patterns among Anolis lizard populations. Am. Nat. 108: 429-442

Roughgarden, J. (1979). Theory of population genetics and evolutionary ecology: an introduction. MacMillan Publ. Co., New York

Ryan, T. A., Jr., Joiner, B. L., Ryan, B. F. (1980). Minitab reference manual. Minitab Project, Pennsylvania State Univ., Univ. Park

Schoener, T. W., Gorman, G. C. (1968). Some niche differences in three Lesser Antillean lizards of the genus Anolis. Ecology 49: 819-830

Shelbourne, J. E. (1962). A predator-prey size relationship for plaice larvae feeding on Oikopleura. J. mar. biol. Assoc U. K. 42: 243-252

Sheldon, R. W., Prakash, A., Sutcliffe, W. H. (1972). The size distribution of particles in the ocean. Limnol. Oceanogr. 17: $327-340$

Sokal, R. R., Rohlf, F. J. (1981). Biometry. 2nd ed. W. H Freeman and Co., San Francisco

Sprules, W. G., Casselman, J. M., Shuter, B. J. (1983). Size distribution of pelagic particles in lakes. Can. J. Fish Aquat. Sci. 40: 1761-1769

Starck, W. A., II, Schroeder, R. E. (1971). Investigations on the grey snapper, Lutjanus griseus Stud. Trop. Oceanogr. (Univ, Miami) 10: 1-224

Stoecker, D. K., Govoni, J. J. (1984). Food selection by young larval gulf menhaden (Brevoortia patronus). Mar. Biol. 80 299-306

Sumida, B. Y., Moser, H. G. (1980). Food and feeding of Pacific hake larvae, Merluccius productus, off southern California and northern Baja California. CalCOFI Rep. 21 : 161-166

Tessier, A. J., Goulden, C. E. (1982). Estimating food limitation in cladoceran populations. Limnol. Oceanogr. 27: $707-717$

Uotani, I:, Matsuzaki, K., Makino, Y., Noda, K., Inamura, O., Horikawa, M. (1981). Food habits of larvae of tunas and their related species in the area northwest of Australia. Bull. Jap. Soc. scient. Fish. 47: 1165-1172 (in Japanese)

Ursin, E. (1973). On the prey size preference of cod and dab. Meddr Danm. Fisk -og Havunders, N. S. 7: 85-98

Villiers, L. (1980). Changes in predation by the juvenile goby Deltentosteus quadrimaculatus (Teleostei, Gobiidae). Neth. J. Sea Res. 14: 362-373

Ware, D. M. (1980). Bioenergetics of stock and recruitment. Can. J. Fish. Aquat. Sci. 37: 1012-1024

Werner, E. A. (1974). The fish size, prey size, handling time relation in several sunfishes and some implications. J. Fish. Res. Bd Can. 31: 1531-1536

Werner, E. A. (1977). Species packing and niche complementarity in three sunfishes. Arn. Nat. 111: 553-578

Yokota, T., Toriyama, M., Kanai, F., Nomura, S. (1961). Studies on the feeding habits of fishes. Rept. Nankai Reg. Fish. Res. Lab. 14: 1-234 (in Japanese)

This paper was presented by Professor P. J. Wangersky; it was accepted for printing on August 23, 1985 